ORIGINAL ARTICLE

\title{
$N F-\kappa B$ in tracheal lavage fluid from intubated premature infants: association with inflammation, oxygen, and outcome
}

A Bourbia, M A Cruz, H J Rozycki

See end of article for authors' affiliations

.....................

Correspondence to: Dr Rozycki, Division of Neonatal-Perinatal Medicine, Department of Pediatrics, Virginia Commonwealth University School of Medicine, Richmond, VA 23298 0276, USA; hrozycki@hsc. vcu.edu

Accepted 11 June 2005 Published online first 27 July 2005
Objectives: To determine if tracheal lavage concentrations of the transcription factor $N F-\kappa B$, which is activated by risk factors associated with bronchopulmonary dysplasia (BPD) and induces expression of cytokines associated with BPD, is related to BPD in premature infants.

Design: Serial tracheal lavage samples from intubated premature infants were analysed for cell count and concentrations of interleukin (IL) 8 and NF- $\mathrm{KB}$, corrected for dilution by secretory component concentrations.

Setting: Level III university hospital neonatal intensive care unit.

Patients: Thirty three intubated infants (mean (SD) birth weight 903 (258) g, median gestation 27 weeks (range 24-31)) in the first 14 days of life.

Main outcome measures: Tracheal effluent NF- $\kappa B$, IL8, and cell counts, corrected for dilution by secretory component measurement.

Results: Square root transformed NF- $\mathrm{KB}$ concentrations were significantly related to signs of inflammation (cell count, $p=0.002 ;$ IL8, $p=0.019$ ) and to simultaneous fraction of inspired oxygen in samples from the first 3 days of life $(r=0.512, p<0.003)$. Of the 32 subjects with samples in the first 3 days of life, the half who either died or had BPD had higher NF- $\kappa B$ concentrations than those without BPD (square root concentration $0.097(0.043) \vee 0.062(0.036) \mu \mathrm{g} / \mu \mathrm{g}$ protein/ $\mu \mathrm{g}$ secretory component, $\mathrm{p}=0.018)$.

Conclusions: Tracheobronchial lavage NF- $\kappa B$ concentrations are related to lung inflammation, oxygen exposure, and pulmonary outcome in intubated preterm infants. NF- $\kappa \mathrm{B}$ activation may be an early critical step leading to BPD.
B ronchopulmonary dysplasia (BPD) occurs primarily in premature infants who are mechanically ventilated and exposed to oxygen early in their life. It is associated with early inflammation of the airways and lung interstitium, mediated by proinflammatory cytokines (interleukin (IL) $1 \beta{ }^{2}$ IL6, ${ }^{3}$ IL8, monocyte chemoattractant protein (MCP) $1,{ }^{4}$ and intercellular adhesion molecule $\left.(\text { ICAM })^{5}\right)$, which are raised in tracheobronchial lavage obtained from patients who progressed to BPD. Expression of these mediators is partially controlled through the activation of transcription factors. These are proteins that, on appropriate stimulation, attach to a recognition sequence in the promoter region of specific genes. ${ }^{6}$ One of these transcription factors is nuclear factorkappa B (NF- $\mathrm{B})$.

$\mathrm{NF}-\kappa \mathrm{B}$, a ubiquitous transcription factor, promotes the expression of many genes, including proinflammatory cytokines associated with the development of BPD. It is activated by a variety of factors, including infectious stimuli, inflammatory cytokines, deformation, oxidants, and other causes of cell stress. ${ }^{78}$ It has roles in controlling apoptosis and cell proliferation and differentiation ${ }^{9}$ and may be involved in lung development. ${ }^{10}$

Activation of NF- $\mathrm{KB}$ occurs in many inflammatory conditions both in vivo and in vitro. Lung macrophages from adults at risk of acute respiratory distress syndrome had significantly more activated NF- $\mathrm{BB}$ than from those who did not develop acute respiratory distress syndrome. ${ }^{11} \mathrm{NF}-\kappa \mathrm{B}$ activation was higher in monocytes and neutrophils in adults with fatal systemic inflammatory response than in those who survived. ${ }^{12}$

As NF- $\kappa B$ is activated by stimuli associated with the development of BPD, promotes the expression of proinflammatory mediators that are increased in the lungs of infants who develop BPD, and has been found in older patients with acute respiratory distress syndrome, we hypothesised that activation of NF- $\kappa B$ may be a critical early step in the pathophysiology of BPD. The two aims of this study were to see if there is increased activation of NF- $\kappa \mathrm{B}$ in tracheal lavage effluent cells from premature infants who develop BPD and to examine if clinical conditions that might activate NF- $\kappa \mathrm{B}$ are related to potential inflammatory consequences of its activation.

\section{METHODS}

\section{Subjects and sampling}

Subjects who were $<1500 \mathrm{~g}$ birth weight and intubated in the first 3 days of life were eligible for enrolment. Exclusion criteria were likely demise and lack of informed consent. Prophylactic surfactant therapy was given to inborn neonates $<30$ weeks gestation, and rescue surfactant provided to all others who were diagnosed with respiratory distress syndrome. Infants weighing $<1000 \mathrm{~g}$ at birth were usually placed on high frequency oscillatory ventilation. Prophylactic indomethacin was given to babies $<30$ weeks gestational age. The study was approved by the institutional review board, and informed consent was obtained from parents before any sampling.

Tracheal lavage fluid during routine suctioning was collected on days $1-2,3,5,7$, and 14 of life if the patient was still intubated. Material was collected using previously

Abbreviations: $\mathrm{BPD}$, bronchopulmonary dysplasia; $\mathrm{FlO}_{2}$, fraction of inspired oxygen; IL, interleukin; NF- $\kappa B$, nuclear factor-kappa B; SC, secretory component 
published methods. ${ }^{2}$ The samples were transported to the laboratory on ice and processed immediately.

A manual white blood cell count was performed. After centrifugation $\left(1200 \mathrm{~g}\right.$ for five minutes at $4^{\circ} \mathrm{C}$ ), protease inhibitors $(1 \mu \mathrm{l} 0.5 \mathrm{M}$ dithiothreitol, $5 \mu \mathrm{l} 100 \mathrm{mM}$ phenylmethanesulphonyl fluoride, $20 \mu \mathrm{l} \mathrm{l} \mathrm{mg} / \mathrm{ml}$ leupeptin, $10 \mu \mathrm{l}$ $5 \mathrm{mg} / \mathrm{ml}$ aprotinin, $10 \mu \mathrm{l} 100 \mathrm{mM}$ benzamidine; all from Sigma, St Louis, Missouri, USA) were added per ml supernatant, and the pelleted cells and supernatant stored at $-80^{\circ} \mathrm{C}$.

\section{Assays}

Nuclear protein was isolated from the thawed cell pellet in the three step process according to the manufacturer's instructions (Nuclear Extract Kit; Activemotif, Carlsbad, California, USA). The protein concentration was determined by Coomassie protein assay. NF- $\mathrm{KB}$ in nuclear protein extract was determined by enzyme linked immunosorbent assay (TransAM NF- $\mathrm{BB}$ p65; Activemotif), again following the manufacturer's instructions. Assay specificity was confirmed using the provided competitive oligonucleotides. The provided HeLa cell extract was used to produce a standard curve. Equal amounts of nuclear protein were used, and the results normalised to both the amount of nuclear protein and the amount of secretory component $(\mathrm{SC})^{13}$ and expressed as $\mu \mathrm{g} /$ $\mu \mathrm{g}$ nuclear protein/ $\mu \mathrm{g}$ SC.

The supernatant was assayed for cytokine IL8 by enzyme linked immunosorbent assay (IL8 Duoset; R \& D Systems, Minneapolis, Minnesota, USA), diluted at a 1:1 to 5:1 diluent to sample ratio using standard diluent to bring the sample concentration into the assay range $25-2000 \mathrm{pg} / \mathrm{ml}$. Samples were run in duplicate. IL8 concentration was expressed as pg/ $\mu \mathrm{g}$ SC.

The concentration of SC in the specimen supernatant was determined using a quantitative sandwich enzyme linked immunosorbent assay. The capture antibody (mouse monoclonal anti-hSC; NI 194-4), detection antibody (horseradish peroxidase conjugated polyclonal goat anti-hSC), and standard (free SC from human milk) were purchased from Accurate Chemical, Westbury, New York, USA.

\section{Clinical data and analysis}

Data on perinatal factors, including infection and steroid use, and concurrent ventilator settings were collected prospectively. The fraction of inspired oxygen $\left(\mathrm{FIO}_{2}\right)$ and ventilatory settings at the time of sampling were used. BPD was defined as a need for supplemental oxygen at 36 weeks postconceptional age to maintain saturations $>92 \%$ as is our general practice. Because they were not normally distributed, NF- $\kappa B$ and IL8 concentrations, cell count, and $\mathrm{FIO}_{2}$ were square root transformed. The subjects were separated into a group who survived without BPD and one with either non-survivors or those with BPD.

Statistical analysis was performed using SigmaStat version 3.0 (SPSS, Inc, Chicago, Illinois, USA) and SAS version 9.1 (SAS Institute, Cary, North Carolina, USA). Unpaired $t$ test and rank sum tests, as well as multiple logistic regression tests, were used. Because the analysis involved multiple samples from individual subjects performed at variable times, the relations between NF- $\mathrm{KB}$ and other lavage variables, including cell count, IL8, and the $\mathrm{FIO}_{2}$ at the time of sampling were analysed using a mixed effects model with a covariance pattern structure using day of sample and length of intubation (as a marker of severity) as covariates. $\mathrm{p}<0.05$ was considered significant, except for regression analysis of day $1-3$ samples, where $p<0.023$ was used to compensate for multiple analyses, as these data were also used in the regression analysis of the complete data set. Means are expressed with associated standard deviations and medians with associated 5th-95th centile.

\section{RESULTS}

Seventy tracheal lavage samples were obtained from 33 subjects. The mean (SD) birth weight was 903 (258) g, and median gestational age was 27 weeks (range 24-31). As lavage was performed only when the patients were intubated, the number of samples declined over time (day $1, \mathrm{n}=23$; day $2, \mathrm{n}=3$; day $3, \mathrm{n}=16$; day $5, \mathrm{n}=11$; day $7, \mathrm{n}=11$; day $14, \mathrm{n}=6$ ). In addition, because samples were collected only when suctioning was performed for clinical indications, some subjects did not have samples available at all the times specified in the protocol.

$\mathrm{NF}-\kappa \mathrm{B}$ was detectable in all samples but was below the assay limit in 11 samples. In these, a value equal to the lowest value in the assay was assigned. IL8 was measured in all lavage samples. Cell counts were not available for four samples. The median amount of NF- $\kappa \mathrm{B}$ in the tracheal lavage samples was $4.51 \mathrm{ng} / \mu \mathrm{g}$ protein/ $\mu \mathrm{g}$ SC (5th-95th centile range 1.25-27.7). Cell count and IL8 concentration were 1.35 cells $/ \mu \mathrm{g}$ SC (5th-95th centile range $0.11-6.32)$ and $4.54 \mathrm{pg} / \mu \mathrm{g}$ SC (5th-95th centile range 0.13-19.29) respectively.

There was no significant difference between the NF- $\mathrm{BB}$ concentrations in the first 3 days of life from the two subjects whose mothers did not receive prenatal steroids compared with the subjects whose mothers were treated (square root $0.043(0.007) v-0.067(0.045) \mu \mathrm{g} / \mu \mathrm{g}$ protein $/ \mu \mathrm{g} \mathrm{SC}, \mathrm{p}=$ $0.425)$, Similarly, samples from the three subjects with culture proven sepsis during the sampling period did not differ significantly from those obtained on the same day from subjects without infection (square root infected 1.47 (0.59) $v$ non-infected $1.60(0.42) \mu \mathrm{g} / \mu \mathrm{g}$ protein/ $\mu \mathrm{g} \mathrm{SC}, \mathrm{p}=0.733)$. Postnatal steroids were given to five subjects during the study period, one on days $3-5$, one on days $6-10$, and three on days 11-13. The last three subjects had mean square root transformed NF- $\mathrm{\kappa B}$ lavage concentrations on day 14 of 1.31 (0.61) compared with $0.98(0.43) \mu \mathrm{g} / \mu \mathrm{g}$ protein $/ \mu \mathrm{g}$ SC in the three subjects who had not received steroids $(\mathrm{p}=0.487)$. It must be noted that, owing to the relatively small number of samples in each condition, the possibility of making either a type I or type II error regarding the effect of infection or steroids is significant.

There were significant relations between the sample NF- $\kappa \mathrm{B}$ concentration and concurrent inflammatory marker (cell count, $F=11.56 \mathrm{p}=0.002$ ) and mediator (IL8, $F=6.06, \mathrm{p}$ $=0.0194)$ in all available lavage samples. The relation between NF- $\mathrm{BB}$ and one potential stimulant, oxidant stress, was evaluated by analysis of NF- $\kappa \mathrm{B}$ concentration in a lavage sample with oxygen concentration at the time of sampling, but was not significantly related using the mixed effects model analysis $\left(\mathrm{FIO}_{2}, F=0.82, \mathrm{p}=0.372\right)$.

To examine whether early NF- $\mathrm{BB}$ activation precedes development of BPD, we focused on the samples obtained in the first 3 days of life and compared the values from subjects who survived without BPD with those from subjects who either died or developed BPD. If a subject had more than one sample obtained during this early period, the results were averaged. In this early set of samples, the transformed NF- $\kappa B$ concentration correlated with $\mathrm{FIO}_{2}(r=0.484, \mathrm{p}=0.005)$, but did not reach the stricter threshold for statistical significance for cell count $(r=0.391, \mathrm{p}=0.033)$ or IL8 $(r$ $=0.375, \mathrm{p}=0.035)$. There was a significant correlation between the individual transformed NF- $\kappa B$ concentrations from days $1-3$ and the transformed IL8 concentration at the subsequent sample - that is, day 1 or $3 \mathrm{NF}-\mathrm{\kappa B}$ and day 3 or 5 IL8 ( $\mathrm{n}=14, r=0.572, \mathrm{p}=0.033$ ).

Of the 32 subjects, two died and 14 were oxygen dependent at 36 weeks postconceptional age (BPD group). The 
Table 1 Clinical characteristics and lavage variables on days 1-3 for the group of infants who did not develop bronchopulmonary dysplasia (No BPD) and the group who died or did develop BPD

\begin{tabular}{llll}
\hline Variable & No BPD & Death or BPD & p Value \\
\hline Total & 16 & 16 & \\
Died & 0 & 2 & 0.002 \\
Birth weight $(\mathrm{g})$ & $1042.8(297.1)$ & $778.4(113.7)$ & $<0.001$ \\
Gestation (weeks) & $28(25.3-30.7)$ & $25.5(24.3-27.7)$ & $<0.001$ \\
Days in $\mathrm{O}_{2}$ & $18.3(16.8)$ & $81.7(16.2)^{*}$ & 0.156 \\
Lavage IL8 $(\mathrm{pg} / \mu \mathrm{g} \mathrm{SC})$ & $2.41(1.68)$ & $1.74(0.77)$ & 0.752 \\
Lavage cell count $(\mathrm{cell} / \mu \mathrm{g} \mathrm{SC})$ & $1.125(0.735)$ & $1.204(0.610)$ & 0.018 \\
Lavage NF-KB $(\mathrm{pg} / \mu \mathrm{g}$ protein $/ \mu \mathrm{g} \mathrm{SC)}$ & $0.062(0.036)$ & $0.097(0.043)$ & \\
\hline
\end{tabular}

Values are mean (SD) or median (5th-95th centile). The lavage variables are square root transformed.

*Does not include the two subjects who died.

IL, interleukin; NF- $\kappa B$, nuclear factor-kappa B; SC, secretory component.

remaining 16 were classified as no BPD. Table 1 compares these two groups. As expected, those in the BPD group were smaller and younger. The groups did not differ with respect to lavage cell count or IL8 concentration. In contrast, NF- $\kappa B$ concentration was higher in the BPD group $(0.097$ (0.043) $v$ $0.062(0.036) \mu \mathrm{g} / \mu \mathrm{g}$ protein $/ \mu \mathrm{g} \mathrm{SC}, \mathrm{p}=0.018)$. However, when gestational age was taken into account using multiple logistic regression, NF- $\mathrm{BB}$ activation was no longer significant.

\section{DISCUSSION}

Inflammation, seen early in BPD, is a complex response to external stimuli. The transcription factor, NF- $\kappa \mathrm{B}$, plays a major role in transducing the stimulus signal(s) into the mediators that promote, modulate, and inhibit the inflammatory response. When activated by environmental stimuli such as shear stress, ${ }^{14}$ oxidants, ${ }^{15}{ }^{16}$ or particles, ${ }^{17}$ or through ligands such as endotoxin, ILl $\beta$, or tumour necrosis factor $\alpha$ attaching to cell surface receptors, ${ }^{18}$ the NF- $\kappa \mathrm{B}$ dimer is translocated to the nucleus where it attaches to a specific DNA sequence in the promoter region to help induce gene expression. Many of the gene products associated with NF$\mathrm{\kappa B}$ have also been associated with $\mathrm{BPD} .^{2-5}{ }^{19}$ In addition, many risk factors for BPD (volutrauma, ${ }^{20}$ infection, ${ }^{18}$ and oxygen $^{16}$ ) can activate NF- $\kappa$ B. In clinical series, NF- $\kappa B$ activation has been found in lung cells of patients with acute respiratory distress syndrome, ${ }^{11}$ chronic obstructive pulmonary disease, ${ }^{21}$ lung transplant, ${ }^{22}$ and asthma, ${ }^{23}$ and the degree of NF- $\kappa \mathrm{B}$ activation correlates with disease severity.

In this study, we examined two questions. Firstly, we found that there was a significantly higher NF- $\kappa \mathrm{B}$ concentration in patients who died or developed BPD than in those who did not. That this difference was influenced by gestational age is consistent with the fact that prematurity is the strongest risk factor for BPD and that inflammation is one of the earliest processes found in those who develop BPD. Secondly, we looked at the relation between the NF- $\kappa B$ concentration in the lavage fluid and other factors in the

\section{What is already known on this topic}

- Early stages of bronchopulmonary dysplasia are associated with raised levels of inflammatory proteins, many of which are controlled, in part, by the transcription factor NF- $\kappa$ B

- Increased amounts of NF- $\kappa$ B have been found in lung lavage cells from patients with lung diseases such as acute respiratory distress syndrome sample, and between the NF- $\mathrm{KB}$ concentration and conditions at the time of sampling to examine clinically some of the possible causes and effects of NF- $\kappa \mathrm{B}$ activation. NF- $\kappa \mathrm{B}$ concentration was related to the amount of oxygen exposure at the time of sampling, consistent with the fact that oxidant stress activates NF- $\kappa \mathrm{B}$. The relation between the transcription factor and an inflammatory mediator, IL8, also agrees with what is known about the consequences of NF- $\kappa B$ activation.

The identity of the cells from which the NF- $\mathrm{BB}$ was extracted was not established in this study because diverting even a small number of cells for a differential cell count might have reduced the yield of nuclear protein below the assay detection limit. As we do not know if these cells were resident-for example, macrophages-or migrated to the lungs-for example, neutrophils-these results, while consistent with the hypothesis that NF- $\kappa \mathrm{B}$ activation leads to lung inflammation and BPD, cannot prove it. That a higher $\mathrm{NF}-\kappa \mathrm{B}$ concentration correlated with a higher IL8 concentration in the sample obtained 48 hours later does support the model of NF- $\kappa \mathrm{B}$ activation preceding and causing inflammatory gene expression. We note that, in vitro, cytokine production occurs in minutes to hours after NF-kB activation but the time course in vivo is less clear.

Because of the episodic nature of sample acquisition, the isolated cells were frozen and then the nuclear protein extracted in a total of two batches. Although this single freeze-thaw cycle could falsely lower the yield of nuclear protein, this seems unlikely, because the cells were thawed only once, because multiple freeze-thaw cycles are needed to

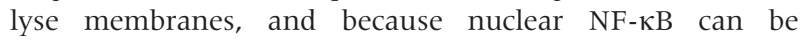
measured on frozen biopsy tissue. ${ }^{24}$

If confirmed, our observations point towards an earlier step in the processes that translate noxious stimuli into inflammation and, ultimately, BPD in the youngest, most vulnerable patients. To determine that NF- $\kappa \mathrm{B}$ activation is, in fact, a critical component of this pathway will require studies in

\section{What this study adds}

- NF- $\kappa \mathrm{B}$ concentrations in cells from tracheal lavage in the first 3 days of life are higher in those premature infants who go on to develop bronchopulmonary dysplasia

- There are higher amounts of NF- $\kappa$ B in tracheal lavage samples from intubated premature infants with increased signs of inflammation and, in the first 3 days of life, who are exposed to higher oxygen concentrations 
which inflammation and BPD are prevented when NF- $\kappa B$ activation is blocked. Several studies have provided some preliminary data supporting this in animals ${ }^{25}$ and in vitro. ${ }^{26}$

\section{ACKNOWLEDGEMENTS}

Supported by an Advancing Newborn Medicine Grant, Forest Pharmaceuticals. We thank the staff of the neonatal intensive care unit at VCU Health Systems for help in collecting the samples, and Rhonda Ellis, Richard Kennedy, and Rong Liu for help with statistical analysis.

\section{Authors' affiliations}

A Bourbia, M A Cruz, H J Rozycki, Virginia Commonwealth University, Richmond, VA 23298-0276, USA

Competing interests: none declared

\section{REFERENCES}

1 Speer CP. New insights into the pathogenesis of pulmonary inflammation in preterm infants. Biol Neonate 2001;79:205-9.

2 Rozycki HJ. Bronchoalveolar interleukin-1 beta in infants on day 1 of life. South Med J 1994:87:991-6.

3 Bagchi A, Viscardi RM, Taciak V, et al. Increased activity of interleukin-6 but not tumor necrosis factor-alpha in lung lavage of premature infants is associated with the development of bronchopulmonary dysplasia. Pediatr Res 1994:36:244-52.

4 Baier RJ, Loggins J, Kruger TE. Monocyte chemoattractant protein-1 and interleukin-8 are increased in bronchopulmonary dysplasia: relation to isolation of Ureaplasma urealyticum. J Investig Med 2001;49:362-9.

5 Ramsay PL, O'Brian Smith E, Hegemier S, et al. Early clinical markers for the development of bronchopulmonary dysplasia: soluble E-Selectin and ICAM-1. Pediatrics 1998; 102:927-32

6 Fan J, Ye RD, Malik AB. Transcriptional mechanisms of acute lung injury. Am J Physiol Lung Cell Mol Physiol 2001;281:L1037-50.

7 Rothwarf DM, Karin M. The NF-kappa B activation pathway: a paradigm in information transfer from membrane to nucleus. Sci STKE 1999:RE1.

8 Uhlig U, Haitsma JJ, Goldmann T, et al. Ventilation-induced activation of the mitogen-activated protein kinase pathway. Eur Respir J 2002;20:946-56.

9 Li X, Stark GR. NFkappaB-dependent signaling pathways. Exp Hematol 2002;30:285-96.
10 Muraoka RS, Bushdid PB, Brantley DM, et al. Mesenchymal expression of nuclear factor-kappa $B$ inhibits epithelial growth and branching in the embryonic chick lung. Dev Biol 2000;225:322-38.

11 Schwartz MD, Moore EE, Moore FA, et al. Nuclear factor-kappa B is activated in alveolar macrophages from patients with acute respiratory distress syndrome. Crit Care Med 1996;24:1285-92.

12 Paterson RL, Galley HF, Dhillon JK, et al. Increased nuclear factor kappa B activation in critically ill patients who die. Crit Care Med 2000;28:1047-51.

13 Dargaville PA, South $M$, Vervaart $P$, et al. Pulmonary surfactant concentration during transition from high frequency oscillation to conventional mechanical ventilation. J Paediatr Child Health 1997;33:517-21.

14 Fisher $\mathbf{A B}, \mathrm{Al}-$ Mehdi $\mathrm{AB}$, Manevich $\mathrm{Y}$. Shear stress and endothelial cell activation. Crit Care Med 2002;30:S192-7.

15 Rozycki HJ, Eischied AC, Huff TR. Effect of hyperoxia on IL-8 expression in premature versus term rabbit lung explants. Exp Lung Res 2004;30:285-96.

16 D'Angio CT, Finkelstein JN. Oxygen regulation of gene expression: a study in opposites. Mol Genet Metab 2000;71:371-80

17 Churg A, Wright JL. Airway wall remodeling induced by occupational mineral dusts and air pollutant particles. Chest 2002;122:306S-309S.

18 Li Q, Verma IM. NF-kappaB regulation in the immune system. Nat Rev Immunol 2002;2:725-34.

19 Tullus K, Noack GW, Burman LG, et al. Elevated cytokine levels in tracheobronchial aspirate fluids from ventilator treated neonates with bronchopulmonary dysplasia. Eur J Pediatr 1996;155:112-16.

20 Held HD, Boettcher S, Hamann L, et al. Ventilation-induced chemokine and cytokine release is associated with activation of nuclear factor-kappaB and is blocked by steroids. Am J Respir Crit Care Med 2001;163:711-16.

21 Di Stefano A Caramori G Oates $T$, et al. Increased expression of nuclear factor-kappaB in bronchial biopsies from smokers and patients with COPD. Eur Respir J 2002;20:556-63.

22 Farver CF, Raychaudhuri B, Malur A, et al. Increased alveolar macrophage nuclear factor-kappa $B$ activation and macrophage inhibitory protein-l alpha levels in lung transplant patients. Transplantation 2000;70:1599-603.

23 Hart LA, Krishnan VL, Adcock IM, et al. Activation and localization of transcription factor, nuclear factor-kappaB, in asthma. Am J Respir Crit Care Med 1998;158:1585-92.

24 Uhlig U, Fehrenbach $\mathrm{H}$, Lachmann RA, et al. Phosphoinositide 3-OH kinase inhibition prevents ventilation-induced lung cell activation. Am J Respir Crit Care Med 2004; 169:201-08.

25 Sadikot RT, Han W, Everhart MB, et al. Selective lkappaB kinase expression in airway epithelium generates neutrophilic lung inflammation. J Immunol 2003;170:1091-8

26 Griesenbach U, Scheid P, Hillery E, et al. Anti-inflammatory gene therapy directed at the airway epithelium. Gene Ther 2000;7:306-13. 